\title{
Lusioersily
}

\section{Functional Requirements for Assistive Technology for People with Cognitive Impairments and Dementia}

Meiland, F. J., de Boer, M. E., van Hoof, J., van der Leeuw, J., Witte, L., Blom, L., Karkowski, I., Mulvenna, M., \& Dröes, R. M. (2012). Functional Requirements for Assistive Technology for People with Cognitive Impairments and Dementia. In R. Wichert, K. Van Laerhoven, \& J. Gelissen (Eds.), Constructing Ambient Intelligence (Vol. 277, pp. 146-151). Springer. https://doi.org/10.1007/978-3-642-31479-7_22

Link to publication record in Ulster University Research Portal

\section{Published in:}

Constructing Ambient Intelligence

Publication Status:

Published (in print/issue): 01/01/2012

DOI:

10.1007/978-3-642-31479-7_22

\section{Document Version}

Author Accepted version

\section{General rights}

Copyright for the publications made accessible via Ulster University's Research Portal is retained by the author(s) and / or other copyright owners and it is a condition of accessing these publications that users recognise and abide by the legal requirements associated with these rights.

\section{Take down policy}

The Research Portal is Ulster University's institutional repository that provides access to Ulster's research outputs. Every effort has been made to ensure that content in the Research Portal does not infringe any person's rights, or applicable UK laws. If you discover content in the Research Portal that you believe breaches copyright or violates any law, please contact pure-support@ulster.ac.uk. 


\title{
Functional Requirements for Assistive Technology for People with Cognitive Impairments and Dementia
}

\author{
F.J.M. Meiland ${ }^{1}$, M.E. de Boer ${ }^{2}$, J. van $\operatorname{Hoof}^{3}$, J. van der Leeuw ${ }^{4}$, L. de Witte ${ }^{5}$, \\ M. Blom ${ }^{6}$, I. Karkowski ${ }^{7}$, M.D. Mulvenna ${ }^{8}$, and R.M. Dröes ${ }^{1}$ \\ ${ }^{1}$ Department of Nursing Home Medicine and Department of Psychiatry, \\ VU University Medical Center, Van der Boechorststraat 7, \\ 1081 BT Amsterdam, The Netherlands \\ $\{\mathrm{fj} . \mathrm{meil}$ and, rm. droes $\}$ avumc.nl \\ ${ }^{2}$ Department of Nursing Home Medicine, VU University Medical Center, \\ Van der Boechorststraat 7, 1081 BT Amsterdam, The Netherlands \\ ${ }^{3}$ Research Centre for Innovation in Health Care, Faculty of Health Care, Hogeschool Utrecht \\ University of Applied Sciences, Bolognalaan 101, 3584 CJ Utrecht, The Netherlands \\ ${ }^{4}$ Vilans, Catharijnesingel 47, 3511 GC Utrecht, The Netherlands \\ ${ }^{5}$ University of Maastricht, Hogeschool Zuyd, Postbus 550, 6400 AN Heerlen, The Netherlands \\ ${ }^{6}$ Alzheimer Nederland, Kosterijland 3, 3981 AJ Bunnik, The Netherlands \\ ${ }^{7}$ TNO, innovation for life, The Hague, The Netherlands \\ ${ }^{8}$ School of Computing and Mathematics, University of Ulster, United Kingdom
}

\begin{abstract}
The amount of technological aids on the market to support people in their everyday functioning is increasing. For example mobile telephone, electronic diary, skyping and domotics. Many of these aids are too complicated to operate for people with cognitive impairments, like dementia. For technology to be practicable and useful for them, it will have to meet certain requirements. This paper addresses the needs and impairments of people with dementia, and the functional requirements for assistive technology for people with dementia.
\end{abstract}

Keywords: assistive technology, dementia, functional requirements.

\section{Introduction}

Today, in 2011, there are some 243,000 people with dementia in the Netherlands. This number will increase explosively to more than half a million people in 2040 due to increased life expectancy and population ageing. Dementia strikes not only the elderly, the disease can also emerge at a younger age. At this moment approx. 12,000 people under the age of 65 have the disease in our country [1].

The increase in numbers of people with cognitive impairments and dementia also increases pressure on the care and welfare services for this target group. This is aggravated by the anticipated relative decrease of available personnel in the care sector. In addition to carers, technological aids will therefore be employed more and more as alternative types of care and support in daily functioning. Technological aids may include, for example, remote care (telecare) and home automation (domotics), where 
e.g. sensors can increase safety in the home, but also simplified mobile telephones, electronic diaries with automatic reminder systems, and videophoning using skype.

The expectation is that people can continue to function safely in their familiar living environment for a longer period of time. However, experience shows that technological aids are often too complicated to operate or learn to operate for cognitively impaired persons, like people with dementia. If they are to be able to use and benefit from the technology, it will have to meet certain requirements.

\section{Needs of People with Cognitive Impairments and Dementia}

To adequately support the growing group of people with cognitive impairment and dementia, it is necessary to understand their needs. Naturally these needs are related first of all to the specific cognitive impairment of the individual, such as memory complaints, problems with language expression and understanding, and problems performing complex tasks, and to the disease that may be causing them. In elderly persons symptoms of old age, such as difficulty walking and poor eyesight, can also play a role. In addition, personal and contextual factors, such as the way an individual deals with his complaints (coping strategies), what he or she considers most important for his/her quality of life and the amount of care one receives, determine what people need.

Research shows that people with dementia and their informal carers need support or assistance in various areas of everyday life, for example preparing food, household chores, memory problems, handling money and mobility. The most frequently mentioned unmet needs are [2]:

- support for memory problems

- information on one's condition and on care and support options

- social contacts and companionship

- monitoring health and safety

- daytime activities

Existing technology can already meet some of these needs [3]. Memory, for example, can be supported by 'electronic reminders' via mobile phone, television or computer ("Your daughter is visiting you this afternoon", "You have an appointment with the doctor at 10 o'clock"). To facilitate keeping in touch with family, friends and acquaintances there are simplified mobile phones and videophones. GPS systems can trace or assist people when they lose their way. And there are sensors that emit a signal when the person forgets to, for example, turn off the gas or the electric kettle, or that even automatically switch off appliances if needed.

Many of these developments are still in their infancy and are far from meeting every need of people with cognitive impairment and dementia (and their informal carers). In part the technology is insufficiently compatible with the possibilities and limitations of this target group. 


\section{Impairments of People with Dementia}

Dementia is not one particular disease with one particular cause; it is a syndrome, i.e. an accumulation of symptoms, especially disorders in cognitive functions (including memory, attention, language, action), that together cause problems in daily functioning. In most cases of dementia, also in the most common type, namely Alzheimer's disease, there is a gradual decline in functioning. Roughly three stages can be distinguished, each with its particular characteristics.

In the first stage (early dementia), people may experience severe forgetfulness, concentration problems, problems with complex and new situations, difficulty managing finances, loss of sense of time, orientation problems, word finding problems and denial of problems.

In the second stage (advanced dementia) people may have no memory of most recent events, problems carrying out activities of daily living, problems with arithmetic, language problems (expression and understanding), personality and behaviour changes and diurnal rhythm disturbed.

In the final stage (severe dementia) symptoms are: loss of communication, largely unaware of surroundings, in need of assistance with most activities of daily living, not recognizing objects, problems controlling movement, incontinence, and loss of decorum.

For this target group, learning to use new aids is therefore (severely) complicated by memory and concentration problems, problems understanding instructions, recognizing objects/images, problems with verbal expression, and problems carrying out complex actions (apraxia). Also, psychological and behaviour problems can affect learning to use different types of assistive technology.

If assistive technology is to be useful for individuals in the different stages of dementia, these limitations must be taken into account when they are developed.

\section{The Development of Assistive Technology}

In the process of developing assistive technological aids the needs and wishes of the users have to be translated into technological requirements that the design of the assistive technology must meet, if it is to be practicable and useful for the target group (see fig. 1)[4,5].

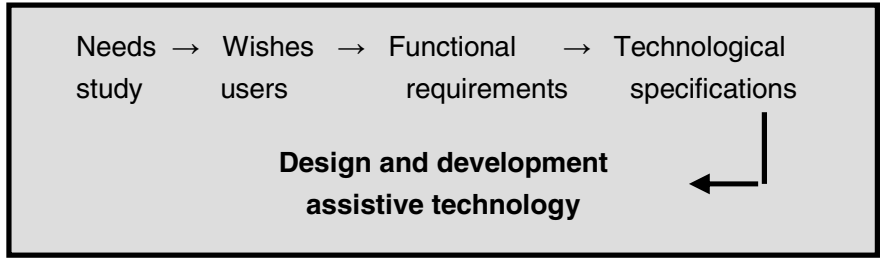

Fig. 1. Process from user wishes to design and development 
An example of a functional requirement is that a reminder for a doctor's appointment must be repeated several times because of the user's short-term memory problems. How this reminder is displayed and how often it is to be repeated, must be determined by the engineers together with domain experts and also in consultation with the end users (people with dementia and the people close to them).

\section{Needs, Aids and Functional Requirements}

Below we present examples of electronic aids that could be used for the most frequently mentioned unmet needs of people with dementia (and their informal carers). For each of the listed aids we have added a brief description of the functional requirements that need to be taken into account when the future users are people with dementia, or their informal carers [6].

\subsection{Need for Assistance with regard to the Symptoms of Dementia}

a. Electronic compensatory aids for impairments such as memory problems in activities of daily living (ADL).

Example: Electronic Memory Aids.

Requirements. Practicability, personal definition of reminders, informal carer controls reminders, repeat option. Interfaces in own language. Preferably multimodal, for example option for vibrate mode in combination with visual and auditory reminder in the case of visual or auditory impairment.

b. Flexible and individually customized electronic aids to support the informal carer in giving instrumental care to the person with dementia.

Example: Remote care services; support and education for informal carers via the internet and telephone.

$>$ Requirements. Possibility to indicate personal preferences, integrated in personal environment.

c. Technological support for people with dementia and informal carers in dealing with behavioural and psychological changes.

Example: Websites; monitoring behaviour with sensors/cameras; influencing behaviour using music.

Requirements. Easily accessible, integrate equipment in personal environment, possibility to indicate personal preference with a user-friendly interface in ones own language.

d. Emotional support for people with dementia and informal carers.

Example: Support via email groups; chat box on Alzheimer sites, etc.

Requirements. Easily accessible, no codes or password, based on once-only registration and, for example, identification of the PC. 


\subsection{Need for Information on one's Condition and on Care and Support Options}

a. Information on dementia

Example: Via Internet.

Requirements. accessible texts and web design of Internet pages, not too childish, in ones own language and limited amount of information on a page.

b. Information on services, legal and financial matters and available care and welfare services.

Example: Digital social map of regional care and welfare services.

$>$ Requirements. Supplied information is accessible and geared to the individual ('customized'); context specific and demand driven.

c. Information on personal condition, care appointments and planning of care. Example: Electronic medical record, electronic patient record.

$>$ Requirements. Remote consultation or at GP's: Actual and comprehensive record with information from most important professional carers.

\subsection{Need for Social Contacts and Companionship}

This concerns ways to stay in contact with family and friends and the social environment.

Example: Telecommunications systems such as simple mobile telephone/skype; touch-screen PCs; tele-visits; robot pets.

$>$ Requirements. Intuitive operation must be possible; preferably the minimum number of buttons; design of operation screen geared to personal preferences.

\subsection{Need for Health Monitoring and Experienced Safety}

The need to be cared for and to be safe as the disease progresses is central here.

Example: Telecare/telemonitoring; fall detection and alert systems for, e.g. fall detection (sensors/cameras), monitoring sleep pattern or vital functions, detection of dangerous situations (e.g. forgetting electric kettle).

Requirements. Geared to the needs of individual and informal carer; context specific; preferably full automatic (no direct input from person with dementia required); flexible and reliable feedback of detected (emergency) situations (depending on personal preferences alert is sent to person with dementia, informal or professional carer); with optimal user-friendliness for person with dementia (meaning also e.g. that professionals treat people well, good installation procedures). 


\subsection{Need for Daytime Activities}

This is about being able to undertake activities to relax and to do something useful.

Example: GPS based tracking systems (e.g. a watch) to allow for outdoor activities (finding and guiding the way back home for people who lost their way); multimedia systems to look at photographs, listen to music or play games.

Requirements. Geared to the needs of the individual; practicability (e.g. simple operation, taking into account memory, visual and auditory impairments); possibility of personalization; in own language; easy to take along; low battery usage.

Finally, it is important to investigate the (cost) effectiveness of the developed technology and, in the case of proven added value, to explore the possibilities of subsidies or reimbursement of costs for cognitively impaired people and their informal carers.

\section{References}

1. http://www.alzheimer-nederland.nl

2. Van der Roest, H.G., Meiland, F.J.M., Comijs, H.C., Derksen, E., Jansen, A.P.D., Van Hout, H.P.J., Jonker, C., Dröes, R.M.: What do community dwelling people with dementia need? A survey among those who are known by care and welfare services. International Psychogeriatrics 21(5), 949-965 (2009) (Epub July 15, 2009)

3. Lauriks, S., Reinersmann, A., van der Roest, H., Meiland, F.J.M., Davies, R.J., Moelaert, F., Mulvenna, M.D., Nugent, C.D., Dröes, R.M.: Review of ICT-based services for identified unmet needs in people with dementia. Ageing Research Reviews 6(3), 223-246 (2007) (Epub August 2, 2007)

4. Hettinga, M., Holthe, H., Andersson, A.L., Moelaert, F.: Managing the transition from user studies to functional requirements to technical specification. In: Mulvenna, M.D., Nugent, C.D. (eds.) Supporting People with Dementia Using Pervasive Health Technologies. Advanced Information and Knowledge Processing. Springer-Verlag London Limited (2010)

5. Meiland, F.J.M., Reinersmann, A., Sävenstedt, S., Bergvall-Kåreborn, B., Hettinga, M., Craig, D., Andersson, A.L., Dröes, R.M.: User-participatory development of assistive technology for people with dementia - from needs to functional requirements. First Results of the COGKNOW Project. Non-pharmacological Therapies in Dementia 1(1), 71-91 (2010)

6. Dröes, R.M., Bentvelzen, S.C.L., Meiland, F., Craig, D.: Dementia-related and other factors to be taken into account when developing ICT-support for people with dementia Lessons from field trials. In: Mulvenna, M.D., Nugent, C.D. (eds.) Supporting People with Dementia Using Pervasive Health Technologies. Advanced Information and Knowledge Processing, ch. 8, pp. 113-130. Springer, London (2010) ISBN: 978-1-84882-550-5 